\title{
Interdose Elevation in Plasma Cortisol During Chronic Treatment with Alprazolam but not Lorazepam in the Elderly
}

\author{
Nunzio Pomara*, ${ }^{*, 2}$, Lisa M Willoughby', James C Ritchie ${ }^{3}$, John J Sidtis ${ }^{1,2}$, David J Greenblatt ${ }^{4}$ and Charles B \\ Nemeroff ${ }^{5}$ \\ 'Geriatric Psychiatry Program, Nathan S Kline Institute for Psychiatric Research, Orangeburg, NY, USA; ${ }^{2}$ Department of Psychiatry, New York \\ University School of Medicine, New York, NY, USA; ${ }^{3}$ Department of Pathology, Emory School of Medicine, Atlanta, GA, USA; ${ }^{4}$ Department of \\ Pharmacology and Experimental Therapeutics, Tufts University School of Medicine Boston, MA, USA; ${ }^{5}$ Department of Psychiatry, Emory School of \\ Medicine, Atlanta, GA, USA
}

\begin{abstract}
Benzodiazepines (BZPs) have been shown to reduce hypothalamic-pituitary-adrenal (HPA) axis activity acutely in normal humans. In contrast, the effects of chronic BZP treatment on the HPA axis have not been well studied, especially in the geriatric population. This study examined the acute and chronic effects (3 weeks) of alprazolam and lorazepam on plasma cortisol in 68 subjects (60-83 years) who received 0.25 or $0.50 \mathrm{mg}$ b.i.d. alprazolam, or 0.50 or $1.0 \mathrm{mg}$ b.i.d. lorazepam, or placebo orally according to a randomized, doubleblind, placebo-controlled parallel design. Memory assessment and blood samples for plasma cortisol were obtained prior to the morning dose on days $0,7,14$, and 21 , and at I, 2.5, and $5 \mathrm{~h}$ postdrug on days 0 and 21 . Assessments of anxiety and depression were carried out at days $0,7,14$, and 21 before drug administration. Plasma cortisol was affected compared to placebo only by the $0.5 \mathrm{mg}$ alprazolam dose. During the first and the last day of treatment, there was a significant drop in cortisol at $2.5 \mathrm{~h}$ after alprazolam compared to placebo. The predose cortisol levels increased significantly during chronic alprazolam treatment, and correlations were found between these cortisol changes and changes in depression, anxiety, and memory scores. These findings suggest that even a short period of chronic treatment with alprazolam, but not lorazepam, may result in interdose HPA axis activation in the elderly, consistent with drug withdrawal. If confirmed, this effect may contribute to an increased risk for drug escalation and dependence during chronic alprazolam treatment. Neuropsychopharmacology (2004) 29, 605-6II, advance online publication, 17 December 2003; doi: I 0.1038/sj.npp. I 300365
\end{abstract}

Keywords: alprazolam; cortisol; elderly; withdrawal; lorazepam; tolerance

\section{INTRODUCTION}

Acute administration of various benzodiazepines (BZPs) has been associated with a decrease in basal plasma cortisol and adrenocorticotropic hormone (ACTH) concentrations, consistent with a decrease in the hypothalamic-pituitaryadrenal (HPA) axis activity (Beary et al, 1983; Boulenger et al, 1989; Bruni et al, 1980; Charney et al, 1986; Curtis et al, 1997; De Souza, 1990; Gram et al, 1984; Laakmann et al, 1984; McIntyre et al, 1993; Osman et al, 1993; Risby et al, 1989; Roy-Byrne et al, 1991; Schuckit et al, 1992; Tormey et al, 1979; Zemishlany et al, 1990). BZPs have also been shown to attenuate or block the increase in plasma cortisol associated with various types of acute stressors, such as

*Correspondence: N Pomara, Geriatric Psychiatry Program, Nathan S. Kline Institute for Psychiatric Research, 140 Old Orangeburg Rd, Bldg. 35, Orangeburg, NY 10962, USA, Tel: + 845398 5579, Fax: + 845 398 5575, E-mail: pomara@nki.rfmh.org

Received 02 July 2003; revised 23 September 2003; accepted 06 November 2003

Online publication: 10 November 2003 at http://www.acnp.org/ citations/Npp I I I 00303294/default.pdf preoperative stress, painful electrical stimulation, hypoglycemia, and metabolic stress (Breier et al, 1991; Collomp et al, 1994; Goldstein et al, 1982; Joyner et al, 1998; Judd et al, 1995; Kertesz et al, 1985; Melsom et al, 1976; Pruneti et al, 2002; Rodriguez-Huertas et al, 1992; Roy-Byrne et al, 1988; Santagostino et al, 1996; Sevy et al, 1994; Torpy et al, 1993, 1994; Vongsavan et al, 1990). Acute doses of both diazepam and alprazolam have been associated with reductions in plasma cortisol, although the effect produced by alprazolam has been more consistent (Breier et al, 1986; De Souza, 1990). Fewer studies have examined the effects of lorazepam, another widely prescribed BZP, on cortisol. Single doses of lorazepam reportedly attenuate cortisol elevations associated with surgical and dental procedures (Kertesz et al, 1985; Loach and Fisher, 1975).

Studies of the effects of BZPs on cortisol and other indices of HPA axis activity have generally been limited to the effects of single acute doses (De Souza, 1990). Data on the influence of chronic BZP treatment remain sparse and the relevant studies have been limited to patients with panic disorder (Abelson et al, 1996; Fukuda et al, 1998; Lopez et al, 1990a). Interestingly, these individuals exhibit baseline 
hypercortisolemia (Lopez et al, 1990a), a potentially confounding effect. Thus, it is not clear whether the reductions in plasma and urinary cortisol concentrations associated with chronic alprazolam treatment reported in these patient populations resulted from the direct action of the BZP on HPA axis activity, an indirect action moderated by a reduction in symptoms, some combination of these possibilities, or other unknown mechanisms.

Another limitation of these studies is that measurements of integrated cortisol secretion did not allow for the detection of potential interdose elevations that might occur during chronic alprazolam treatment. Abrupt withdrawal and gradual tapering of alprazolam and other shortelimination half-life BZPs have been shown to result in increased cortisol secretion and activation of other indices of HPA axis activity (Lopez et al, 1990b; Mellman and Uhde, 1986; Owens et al, 1991). Thus, given the relatively short elimination half-life of alprazolam and a prolonged interdose interval, it is possible that a marked drop in plasma drug concentration could trigger increased HPA axis activity in the period prior to morning dose. Indeed, clinical data from individuals on chronic treatment with alprazolam and similar BZPs suggest that rebound anxiety and other symptoms of withdrawal reactions can develop between doses (Ashton, 1994; Cole and Kando, 1993; Hallstrom and Lader, 1981; Herman et al, 1987; Kales et al, 1983, 1987; Noyes et al, 1985, 1988; Pecknold, 1993; Risse et al, 1990; Schweizer and Rickels, 1998; Slak, 1986; Vgontzas et al, 1995; Woods et al, 1992; Wolf and Griffiths, 1991). However, it appears that none of these studies have examined interdose plasma cortisol levels. Additionally, the few studies that have reported reductions in cortisol during chronic alprazolam treatment provided no information on the relationship between drug sampling times and the times at which the last drug dose was administered. Without considering this temporal information, it is possible that the reduced cortisol levels reported during chronic alprazolam treatment simply reflect measurements at plasma drug concentrations.

There are also little data on tolerance with respect to cortisol during chronic BZP treatment. Cowley et al (1995) examined the effects of an acute challenge of diazepam in a group of panic disorder patients on chronic treatment with alprazolam compared to a group that was drug-naive with respect to the use of BZPs. Although diazepam produced comparable reductions in plasma cortisol in the two groups, diazepam-related impairments in saccadic eye velocity and short-term memory were found only in BZP-naive patients. These results suggest that tolerance might have developed to cognitive sequelae, but not to cortisol reduction.

Another limitation to the available data on the effects of BZPs on HPA axis activity is that most studies have employed younger populations and higher doses than those typically recommended in the geriatric population. The relationship of cortisol responses to the dose, dosing schedule, duration of treatment, and potency of BZPs in the geriatric population remains to be clarified. In the light of these considerations, we examined the acute effects of low and high equivalent dosages of alprazolam $(0.25$ and $0.50 \mathrm{mg}$ ) and lorazepam $(0.50$ and $1 \mathrm{mg})$ on plasma cortisol concentrations in a group of normal healthy elderly volunteers as part of a study examining the cognitive effects of these medications.

\section{METHODS}

\section{Subjects}

In total, 82 subjects participated in a study examining the effects of alprazolam and lorazepam on cognitive performance in the elderly (see Pomara et al, 1998 for further details). Complete sets of plasma cortisol levels were available for a subgroup of 68 subjects for the initial challenge session, for 58 subjects during chronic treatment, and for 61 subjects during acute rechallenge. These subjects were 60-83 years of age and all were free of significant psychiatric illness determined by DSM-III-R criteria (American Psychiatric Association, 1987) based on psychiatric interview, Hamilton Anxiety scores (HAM-A), and Hamilton Depression scores (HAM-D). At screening, it was determined that all subjects attained a memory quotient (Wechsler, 1945) score not less than 1 SD below agecorrected scores (Hulicka, 1966) and a vocabulary agecorrected scaled score greater than 7 (Wechsler, 1981). All subjects were free of significant medical illness determined by physical examination, EKG, and routine laboratory investigation. As indicated in Table 1, no difference in demographic or cognitive performance at screening was detected across study medication groups included in these analyses.

\section{Design and Procedures}

A double-blind, placebo-controlled, parallel-groups design was used in this study. Subjects were randomly assigned to receive one of the following study medications orally twice daily at 0900 and 2200 for 3 weeks: $0.25 \mathrm{mg}$ alprazolam, $0.50 \mathrm{mg}$ alprazolam, $0.50 \mathrm{mg}$ lorazepam, $1 \mathrm{mg}$ lorazepam, or placebo. Responses to the morning dose of study medication were measured at $1,2.5$, and $5 \mathrm{~h}$ subsequent to the first b.i.d. dose on days 0 and 21. During chronic treatment, measurements were taken in the mornings prior to administration of the study medication on days $0,7,14$, and 21. At each evaluation time, blood was drawn for determination of plasma cortisol and drug levels. Cortisol was measured by a competitive protein-binding method with a sensitivity of $0.45 \mu \mathrm{g} / \mathrm{dl}$. Crossreactivity with endogenous steroids was less than $1 \%$, except for 11deoxycortisol (4.7\%) and corticosterone (4.5\%). Plasma alprazolam and lorazepam levels were determined by electron capture gas chromatography (Greenblatt et al, 1978). A neuropsychological test battery described in Pomara et al, 1998 was administered during each evaluation time point, with the HAM-A and HAM-D Scales administered only during morning predrug evaluation sessions. In this report, components of the Buschke Selective Reminding Test (BSRT; Buschke and Fuld, 1974), self-reports of mood (Berchou and Block, 1983), and the Hamilton scales were included in the analyses.

\section{Analyses}

The mean plasma cortisol levels for all assessment times are presented in Table 2. The plasma cortisol levels under a particular drug condition $(0.25 \mathrm{mg}$ alprazolam, $0.50 \mathrm{mg}$ alprazolam, $0.50 \mathrm{mg}$ lorazepam, or $1.0 \mathrm{mg}$ lorazepam) were compared to the placebo using analyses of variance 
Table I Demographic and Cognitive Performance at Screening Standard Deviations (in italics)

\begin{tabular}{|c|c|c|c|c|c|c|c|c|c|c|c|}
\hline & \multicolumn{2}{|c|}{$\begin{array}{l}\text { Low alprazolam } \\
(0.25 \mathrm{mg})(\mathrm{N}=\mathrm{I} \mathrm{I})\end{array}$} & \multicolumn{2}{|c|}{$\begin{array}{l}\text { High alprazolam } \\
(0.50 \mathrm{mg})(N=15)\end{array}$} & \multicolumn{2}{|c|}{$\begin{array}{l}\text { Low lorazepam } \\
(0.50 \mathrm{mg})(N=14)\end{array}$} & \multicolumn{2}{|c|}{$\begin{array}{l}\text { High lorazepam } \\
(1.0 \mathrm{mg})(\mathrm{N}=\mathrm{I} 3)\end{array}$} & \multicolumn{2}{|c|}{ Placebo $(N=15)$} & \\
\hline & $\mathbf{M}$ & SD & $\mathbf{M}$ & SD & $\mathbf{M}$ & SD & $\mathbf{M}$ & SD & $\mathbf{M}$ & SD & \\
\hline Age (years) & 68.82 & 6.08 & 68.07 & 5.91 & 68.14 & 5.99 & 67.62 & 4.82 & 69.07 & 6.32 & $F(4,63)=0.14, p=0.97$ \\
\hline Weight (lbs) & $178.43^{\mathrm{a}}$ & 11.29 & 168.03 & 31.63 & 170.07 & 24.82 & $173.67^{\mathrm{a}}$ & 18.29 & 174.90 & 27.81 & $F(4,6 I)=0.25, p=0.91$ \\
\hline MMSE $^{b}$ & 29.29 & 1.11 & 29.33 & 1.32 & 29.13 & 0.99 & 29.56 & 0.53 & 29.56 & 0.73 & $F(4,37)=0.31, p=0.87$ \\
\hline Memory Quotient & 132.05 & 13.65 & 120.27 & 18.01 & $118.92^{\mathrm{a}}$ & 11.55 & $121.33^{\mathrm{a}}$ & 16.20 & $126.29^{\mathrm{a}}$ & 15.36 & $F(4,60)=1.50, p=0.21$ \\
\hline Vocabulary & 13.27 & 2.28 & 13.53 & 2.29 & 13.50 & 3.01 & 13.38 & 2.66 & 13.40 & 3.20 & $F(4,63)=0.02, p=0.99$ \\
\hline HAM-A & 2.81 & 2.79 & $2.14^{\mathrm{a}}$ & 2.11 & 2.79 & 1.42 & 2.62 & 2.26 & $2.07^{\mathrm{a}}$ & 1.86 & $F(4,6 I)=0.38, p=0.82$ \\
\hline HAM-D & 2.09 & 1.81 & 2.47 & 2.50 & 2.50 & 1.99 & 2.23 & 2.13 & $2.21^{\mathrm{a}}$ & 2.39 & $F(4,62)=0.08, p=0.99$ \\
\hline $\operatorname{Sex}(M / F)$ & $7 / 4$ & & $8 / 7$ & & $8 / 6$ & & $8 / 5$ & & $8 / 7$ & & $\chi^{2}(4)=0.49, p=0.98$ \\
\hline
\end{tabular}

aalues based on $n-1$.

balues based on $n=7$ for low alprazolam, $n=8$ for low lorazepam, and $n=9$ for high alprazolam, lorazepam, and placebo.

(ANOVAs) with time as a repeated variable during postdose evaluation sessions. The main effects of drug type and interactions between drug type and time were followed up with $t$-tests comparing a particular drug condition to placebo at each evaluation time. Associations between plasma cortisol concentrations and various measures of Pearson's correlation coefficients were reported.

\section{RESULTS}

Plasma drug levels for 0.25 and $0.50 \mathrm{mg}$ doses of alprazolam significantly differed from one another at all time points, as did plasma drug levels for 1.0 and $0.50 \mathrm{mg}$ doses of lorazepam. As expected, plasma drug levels for high doses were significantly different from low doses at each comparison time (all $t$-tests, $p<0.05$ ), and plasma drug levels from 2.5 to $5 \mathrm{~h}$ postdrug in all conditions (all $t$-tests, $p<0.05$ ). Peak drug levels were consistent with the literature and occurred roughly around 1 and $2.5 \mathrm{~h}$ following the morning dose.

\section{Cortisol Levels Associated with the Initial Acute Morning Dose (Day 0)}

Plasma cortisol levels are presented in Table 2 and repeated measures ANOVAs comparing high or low doses of either alprazolam or lorazepam to placebo across evaluation times during the initial acute challenge revealed that significant drug effects occurred only during the high-dose alprazolam condition (drug type by time, $\mathrm{F}(3,84)=3.05, p=0.033$ ). Paired comparisons indicated that $0.50 \mathrm{mg}$ alprazolam resulted in significantly lower plasma cortisol levels $2.5 \mathrm{~h}$ postdrug when compared to placebo $(t(28)=2.62$, $p=0.0140$. Analyses repeated using change from baseline cortisol levels produced similar results.

\section{Effect of Chronic Treatment on Morning PreDrug Plasma Cortisol Levels}

A within-group analysis showed that at the end of 3 weeks of chronic treatment (on day 21) in the $0.50 \mathrm{mg}$ alprazolam group, the morning predrug plasma cortisol levels were significantly higher than those prior to receiving any treatment on day $0(t(11)=3.14, p=0.011)$. No significant difference between predrug plasma cortisol levels pre- and postchronic treatment was noted in the placebo or other drug groups was seen. There were no drug-to-placebo differences in predrug cortisol levels on days $0,7,14$, and 21 .

\section{Cortisol Levels Associated with the Final Acute Morning Dose (Day 21)}

After 3 weeks of chronic b.i.d. treatment, plasma cortisol levels following the morning dose of preassigned drug were measured during the final session on day 21 . Repeated measures ANOVA comparing cortisol levels following high or low doses of either alprazolam or lorazepam to placebo revealed evidence that significant drug effects occurred in the high-dose alprazolam group (drug type by time, $\mathrm{F}(3,69)=4.86, p=0.004)$. Follow-up $t$-tests indicated that the lowered plasma cortisol levels observed in the $0.50 \mathrm{mg}$ alprazolam group compared to the placebo approached significance at the $2.5 \mathrm{~h}$ test time $(t(23)=1.95, p=0.064)$. ANOVAs performed on change from baseline cortisol levels comparing $0.5 \mathrm{mg}$ alprazolam to the placebo also produced a significant drug by time interaction $(\mathrm{F}(2,46)=5.06$, $p=0.010$ ), in that the magnitude of reduction in cortisol levels in the high-dose alprazolam condition was greater than the placebo at $2.5 \mathrm{~h}$ postdrug $(t(23)=2.78, p=0.011)$.

\section{Day 0 (Initial Challenge) vs Day 21 (Final Challenge) Cortisol Levels Associated with the Morning Dose}

The extent to which cortisol levels after the morning dose changed after chronic treatment within each drug condition was examined by ANOVAs with postdrug evaluation time $(0,1,2.5$, and $5 \mathrm{~h})$ and day $(0$ and 21$)$ as repeated variables. There was a significant day by time interaction for the $0.50 \mathrm{mg}$ alprazolam condition $(\mathrm{F}(3,33)=3.47, p=0.027)$. Paired $t$-tests indicated that cortisol levels were significantly higher during day 21 than day 0 at $1 \mathrm{~h}(t(11)=2.87$, $p=0.015)$ and at $2.5 \mathrm{~h}$ postdrug $9 t(11)=2.26, p=0.045)$. Owing to the previously noted elevation in the morning 
Table 2 Means and Standard Deviations (in italics) of Plasma Cortisol Levels ( $\mu \mathrm{g} / \mathrm{dl}$ ) for the Acute, Chronic, and Final Challenge Sessions

\begin{tabular}{|c|c|c|c|c|c|c|c|c|c|c|}
\hline & \multicolumn{2}{|c|}{$\begin{array}{l}\text { Low alprazolam } \\
(0.25 \mathrm{mg})\end{array}$} & \multicolumn{2}{|c|}{$\begin{array}{l}\text { High alprazolam } \\
\quad(0.50 \mathrm{mg})\end{array}$} & \multicolumn{2}{|c|}{$\begin{array}{l}\text { Low Lorazepam } \\
(0.50 \mathrm{mg})\end{array}$} & \multicolumn{2}{|c|}{$\begin{array}{l}\text { High lorazepam } \\
\quad(1.0 \mathrm{mg})\end{array}$} & \multicolumn{2}{|c|}{ Placebo } \\
\hline & M & SD & $M$ & SD & $M$ & SD & $\mathbf{M}$ & SD & $M$ & SD \\
\hline $\begin{array}{l}\text { Initial acute } \\
\text { challenge }\end{array}$ & \multicolumn{2}{|c|}{$n=11$} & \multicolumn{2}{|c|}{$n=15$} & \multicolumn{2}{|c|}{$n=14$} & \multicolumn{2}{|c|}{$n=13$} & \multicolumn{2}{|c|}{$n=15$} \\
\hline Baseline & $|4.2|$ & 4.64 & 15.60 & 7.42 & 13.78 & 6.82 & 14.13 & 3.34 & 15.47 & 7.58 \\
\hline $2.5 \mathrm{~h}$ postdrug & 10.92 & 4.44 & 6.75 & 3.13 & 12.87 & 5.60 & 14.68 & 5.12 & 13.54 & 9.55 \\
\hline $5 \mathrm{~h}$ postdrug & 9.69 & 3.59 & 10.65 & 6.24 & 9.38 & 5.13 & 10.29 & 2.90 & 11.94 & 5.56 \\
\hline Chronic treatment & \multicolumn{2}{|c|}{$n=10$} & \multicolumn{2}{|c|}{$n=11$} & \multicolumn{2}{|c|}{$n=13$} & \multicolumn{2}{|c|}{$N=\mid 1$} & \multicolumn{2}{|c|}{$n=13$} \\
\hline Baseline & 13.72 & 4.57 & 13.65 & 6.43 & 13.39 & 6.94 & $|4.0|$ & 3.55 & 15.78 & 7.70 \\
\hline $\begin{array}{l}\text { Final acute } \\
\text { challenge }\end{array}$ & \multicolumn{2}{|c|}{$n=10$} & \multicolumn{2}{|c|}{$n=12$} & \multicolumn{2}{|c|}{$n=14$} & \multicolumn{2}{|c|}{$n=12$} & \multicolumn{2}{|c|}{$n=13$} \\
\hline Baseline & 13.19 & 4.03 & 20.20 & 8.17 & 14.10 & 4.20 & 14.36 & 4.97 & 17.69 & 6.08 \\
\hline I h postdrug & 9.07 & 3.56 & 11.72 & 5.71 & 9.45 & 3.53 & 10.02 & 3.59 & 10.80 & 4.89 \\
\hline $2.5 \mathrm{~h}$ postdrug & 9.94 & 3.70 & 9.38 & 5.10 & 11.53 & 6.63 & 12.76 & 5.12 & 14.15 & 6.94 \\
\hline $5 \mathrm{~h}$ postdrug & 9.68 & 4.44 & 9.50 & 3.85 & | 1.07 & 5.44 & 12.20 & 4.06 & 11.25 & 4.60 \\
\hline
\end{tabular}

cortisol levels during chronic treatment, when changes from baseline scores were examined, the cortisol suppression effect appeared larger on day 21 compared to day 0 .

\section{Plasma Drug Levels with $0.50 \mathrm{mg}$ Alprazolam}

An ANOVA with session (initial and final challenge) and evaluation time as repeated variables was performed on the $0.5 \mathrm{mg}$ alprazolam group. A main effect of session was found when prechallenge baselines were included in the model $(\mathrm{F}(1,11)=69.78, p<0.001)$ as well as when they were excluded from the model $(\mathrm{F}(1,11)=63.79, p<0.001)$, indicating that postdrug plasma drug levels during final challenge were significantly higher than during initial challenge. However, correlational analyses revealed that cortisol levels were not significantly associated with plasma alprazolam concentrations either at $2.5 \mathrm{~h}$ postdrug during the initial and final challenge sessions or during the course of chronic treatment.

\section{Anxiety and Depression Under Chronic $0.5 \mathrm{mg}$. Alprazolam Treatment}

Anxiety (HAM-A) and depression (HAM-D) scores were determined prior to morning dose and repeated measures ANOVAs detected no differences between $0.5 \mathrm{mg}$ alprazolam and placebo groups in change from day 0 anxiety or depressions levels. However, after 2 weeks of chronic treatment of $0.5 \mathrm{mg}$ alprazolam, changes from day 0 anxiety scores were linearly correlated to change from day 0 cortisol levels $(r=0.66, p=0.028)$. Similarly, at 3 weeks, changes in depression scores were associated with changes in cortisol levels $(r=0.61, p=0.048)$. Analysis of change from day 0 self-rated evaluations of sedation (alert-drowsy) indicated a significant time by treatment type interaction $(\mathrm{F}(2,44)=3.46, p=0.040)$, with evidence of reduced alertness in the $0.5 \mathrm{mg}$ alprazolam group relative to the placebo after 2 weeks of chronic treatment $(t(21)=2.47, p=0.022)$. However, this alprazolam-associated change in sedation was not significantly correlated with change in cortisol levels at 2 weeks. Comparison of changes in self-rated tension (tense-relaxed) under chronic $0.5 \mathrm{mg}$ alprazolam treatment to placebo indicated no differences, and no correlations with cortisol levels were detected.

\section{Cortisol Levels and Memory following Chronic $0.5 \mathrm{mg}$ Alprazolam Treatment}

At the end of 21 days chronic treatment of $0.50 \mathrm{mg}$ alprazolam, correlations between plasma cortisol levels and BSRT recall performance indicated that higher morning cortisol levels were significantly associated with higher preand $2.5 \mathrm{~h}$ postdrug delayed recall scores $(r=0.79, p=0.002$ and $r=0.59, p=0.044$, respectively). No such relationships were observed at the initial challenge on day 0 . Total recall was not associated with plasma cortisol levels during either challenge session.

\section{DISCUSSION}

Consistent with previous results, we found that acute and chronic administration of alprazolam $(0.5 \mathrm{mg})$ resulted in significant reductions in plasma cortisol. In addition, we 
found that predose, morning cortisol levels also progressively increased in the 3 -week period of alprazolam $(0.5 \mathrm{mg})$ b.i.d. treatment. These predose, morning elevations were correlated with increased anxiety after 2 weeks of treatment and with increased depression after 3 weeks. Increases in cortisol levels on the 3rd week were associated with better memory performance in response to acute alprazolam rechallenge. Thus, although cortisol dropped following the morning dose of alprazolam, during the course of chronic treatment cortisol actually increased prior to the morning dose.

The possible mechanisms for the observed elevation in plasma morning cortisol are not clear. Pharmacokinetic analysis revealed that alprazolam plasma concentrations markedly decreased by the fifth hour following acute dosing, and very low through levels were likely reached the following morning (ie more than $12 \mathrm{~h}$ after the last dose). The elevation in morning cortisol might reflect early stages of alprazolam withdrawal. Indeed, BZP discontinuation has been associated with drug withdrawal and activation of the HPA axis (Lopez et al, 1990b; Mellman and Uhde, 1986; Owens et al, 1991). In our study, cortisol elevations were not associated with significant increases in other symptoms of withdrawal, but this could be due to the fact that this investigation was not specifically designed to address this question.

Alternatively, it is possible that activation of the HPA axis is the earliest manifestation of withdrawal. There are clinical data suggesting that even short-term treatment with alprazolam can result in the development of dependence and symptoms of anxiety in between doses (Woods et al, 1992).

It is also the case that both endogenous cortisol and alprazolam are substrates for cytochrome P450-3A4 (CYP3A4), which is responsible for metabolism to $6 \beta$ hydroxycortisol and 4 - and $\alpha$-hydroxyalprazolam (Ged et al, 1989; von Moltke et al, 1994). There is evidence that CYP3A4 can accommodate more than one substance and that interactions with a particular substrate can impact on the metabolism of the other (Wang et al, 2000). Thus, the possibility that the elevation in cortisol that we observed during chronic alprazolam treatment might have been related to a partial inhibition of CYP3A4-mediated cortisol metabolism cannot be excluded and deserves further study.

Our findings that chronic alprazolam treatment resulted in a progressive increase in predose cortisol levels contrasts with previous reports that chronic alprazolam treatment was associated with significantly lower plasma or urinary free cortisol relative to the predrug baseline (Abelson et al, 1996; Lopez et al, 1990a). The reasons for the discrepancy may be attributable to several methodological differences, such as uncontrolled dose-to-sampling intervals for cortisol determination, differences in target population, prior use of psychotropic medications, inclusion of placebo group, and pharmacokinetic factors.

Whereas the predose cortisol increases suggest a withdrawal effect, the present results also reflect the development of cognitive tolerance. This was indicated by the absence of significant drug effects on the total and delayed recall in response to the final alprazolam rechallenge (Pomara et al, 1998). Similarly, Cowley et al, (1995) found that panic-disorder patients chronically treated with alpra- zolam experienced reduced cognitive side effects after an acute diazepam challenge. Both withdrawal and tolerance may reflect adaptation to chronic alprazolam treatment that might contribute to dose escalation.

Neither the low alprazolam nor the high and low lorazepam dose had any significant effect on plasma cortisol either acutely or during chronic treatment. The reductions in plasma cortisol that have been reported in response to acute doses of these compounds have involved higher doses than those employed in the current study. For instance, Loach and Fisher (1975) reported that $1.5 \mathrm{mg}$ of lorazepam attenuated cortisol response to presurgical stress and, more recently, Collomp et al (1994) reported a similar effect of a $2 \mathrm{mg}$ lorazepam dose on the cortisol response to exercise. The lack of a significant cortisol response to lorazepam in the present report may well be due to the low doses used. Additionally, although anxiolytic activity of a $1.0 \mathrm{mg}$ lorazepam dose is generally thought to be equivalent to $0.50 \mathrm{mg}$ alprazolam (Ashton, 1994), only the latter resulted in reduced plasma cortisol levels. Thus, it is possible that nonequivalence of doses, or differences in potency, and/or in their intrinsic pharmacological effects in geriatric subjects might have contributed to these observations.

In summary, our results suggest that chronic treatment with alprazolam, but not lorazepam, is associated with plasma cortisol elevations prior to the first morning dose. This increase may reflect an early stage of drug withdrawal. At the same time, a tolerance for cognitive toxicity appears to develop. Since alprazolam and lorazepam remain widely prescribed BZPs and are often taken for months or years, especially in the elderly, it is of potential clinical significance to confirm the differential effects on interdose cortisol levels and HPA axis activation. This may lead to a better understanding of factors that may contribute to an increased risk for drug escalation and dependence during chronic treatments with these compounds.

\section{ACKNOWLEDGEMENTS}

We thank Dr Bruno P Imbimbo from Chiesi Farmaceutici, Parma, Italy, for valuable comments on earlier versions of this manuscript. This study was supported in part by Grant R01 MH42499 (NP), MH42088 (CBN), and MH52899 (CBN)

\section{REFERENCES}

Abelson JL, Curtis GC, Cameron OG (1996). Hypothalamicpituitary-adrenal axis activity in panic disorder: effects of alprazolam on $24 \mathrm{~h}$ secretion of adrenocorticotropin and cortisol. J Psychiatr Res 30: 79-93.

American Psychiatric Association (1987). Diagnostic and Statistical Manual of Mental Disorders, revised 3rd edn. American Psychiatric Press: Washington, DC, USA.

Ashton H (1994). Guidelines for the rational use of benzodiazepines. When and what to use. Drugs 48: 25-40.

Beary MD, Lacey JH, Bhat AV (1983). The neuro-endocrine impact of 3-hydroxy-diazepam (temazepam) in women. Psychopharmacology (Berlin) 79: 295-297.

Berchou R, Block RI (1983). Use of computerized psychomotor testing in determining CNS effects of drugs. Percept Mot Skills 57: 691-700.

Boulenger JP, Squillace K, Simon P, Herrou M, Leymarie P, Zarifian E (1989). Buspirone and diazepam: comparison of 
subjective, psychomotor and biological effects. Neuropsychobiology 22: 83-89.

Breier A, Charney DS, Heninger GR (1986). Intravenous diazepam fails to change growth hormone and cortisol secretion in humans. Psychiatry Res 18: 293-299.

Breier A, Davis OR, Buchanan RW (1991). Alprazolam attenuates metabolic stress-induced neuroendocrine and behavioral effects in humans. Psychopharmacology (Berlin) 104: 479-484.

Bruni G, Dal Pra P, Dotti MT, Segre G (1980). Plasma ACTH and cortisol levels in benzodiazepine treated rats. Pharmacol Res Commun 12: 163-175.

Buschke H, Fuld PA (1974). Evaluating storage, retention, and retrieval in disordered memory and learning. Neurology 24 1019-1025.

Charney DS, Breier A, Jatlow PI, Heninger GR (1986). Behavioral, biochemical, and blood pressure responses to alprazolam in healthy subjects: interactions with yohimbine. Psychopharmacology (Berlin) 88: 133-140.

Cole JO, Kando JC (1993). Adverse behavioral events reported in patients taking alprazolam and other benzodiazepines. J Clin Psychiatry 54(Suppl): 49-61.

Collomp K, Fortier M, Cooper S, Long A, Ahmaidi S, Prefaut C et al (1994). Performance and metabolic effects of benzodiazepine during submaximal exercise. J Appl Physiol 77: 828-833.

Cowley DS, Roy-Byrne PP, Radant A, Ritchie JC, Greenblatt DJ, Nemeroff CB et al (1995). Benzodiazepine sensitivity in panic disorder: effects of chronic alprazolam treatment. Neuropsychopharmacology 12: 147-157.

Curtis GC, Abelson JL, Gold PW (1997). Adrenocorticotropic hormone and cortisol responses to corticotropin-releasing hormone: changes in panic disorder and effects of alprazolam treatment. Biol Psychiatry 41: 76-85.

De Souza EB (1990). Neuroendocrine effects of benzodiazepines. J Psychiatr Res 24(Suppl 2): 111-119.

Fukuda M, Takazawa S, Nakagome K, Iwanami A, Hata A, Kasai K et al (1998). Decreased plasma cortisol level during alprazolam treatment of panic disorder: a case report.. Prog Neuropsychopharmacol Biol Psychiatry 22: 909-915.

Ged C, Rouillon JM, Pichard L, Combalbert J, Bressot N, Bories P et al (1989). The increase in urinary excretion of 6 betahydroxycortisol as a marker of human hepatic cytochrome P450IIIA induction. Br J Clin Pharmacol 28: 373-387.

Goldstein DS, Dionne R, Sweet J, Gracely R, Brewer Jr B, Gregg R et al (1982). Circulatory, plasma catecholamine, cortisol, lipid, and psychological responses to a real-life stress (third molar extractions): effects of diazepam sedation and of inclusion of epinephrine with the local anesthetic. Psychosom Med 44: 259-272.

Gram LF, Christensen L, Kristensen CB, Kragh-Sorensen P (1984). Suppression of plasma cortisol after oral administration of oxazepam in man. $\mathrm{Br} J$ Clin Pharmacol 17: 176-178.

Greenblatt DJ, Franke K, Shader RI (1978). Analysis of lorazepam and its glucuronide metabolite by electron-capture gas-liquid chromatography. Use in pharmacokinetic studies of lorazepam. J Chromatogr 146: 311-320.

Hallstrom C, Lader M (1981). Benzodiazepine withdrawal phenomena. Int Pharmacopsychiatry 16: 235-244.

Herman JB, Brotman AW, Rosenbaum JF (1987). Rebound anxiety in panic disorder patients treated with shorter-acting benzodiazepines. J Clin Psychiatry 48(Suppl): 22-28.

Hulicka IM (1966). Age differences in Wechsler Memory Scale scores. J Genet Psychol 109: 135-145.

Joyner JM, Grice JE, Hockings GI, Torpy DJ, Crosbie GV, Walters MM et al (1998). Inhibition of naloxone-stimulated adrenocorticotropin release by alprazolam in myotonic dystrophy patients. J Neuroendocrinol 10: 391-395.

Judd SJ, Wong J, Saloniklis S, Maiden M, Yeap B, Filmer S et al (1995). The effect of alprazolam on serum cortisol and luteinizing hormone pulsatility in normal women and in women with stress-related anovulation. J Clin Endocrinol Metab 80: 818-823.

Kales A, Bixler EO, Vela-Bueno A, Soldatos CR, Manfredi RL (1987). Alprazolam: effects on sleep and withdrawal phenomena. J Clin Pharmacol 27: 508-515.

Kales A, Soldatos CR, Bixler EO, Kales JD (1983). Early morning insomnia with rapidly eliminated benzodiazepines. Science 220: 95-97.

Kertesz A, Falkay G, Boros M (1985). The effects of benzodiazepines as anaesthesia inducing agents on plasma cortisol level in elective hysterectomy. Acta Med Hung 42: 145-152.

Laakmann G, Wittmann M, Gugath M, Mueller OA, Treusch J, Wahlster $U$ et al (1984). Effects of psychotropic drugs (desimipramine, chlorimipramine, sulpiride and diazepam) on the human HPA axis. Psychopharmacology (Berlin) 84: 66-70.

Loach A, Fisher A (1975). Lorazepam as a premedicant for daycase surgery: an assessment. Anaesthesia 30: 545-549.

Lopez AL, Kathol RG, Noyes Jr R (1990a). Reduction in urinary free cortisol during benzodiazepine treatment of panic disorder. Psychoneuroendocrinology 15: 23-28.

Lopez F, Miller LG, Greenblatt DJ, Chesley S, Schatzki A, Shader RI (1990b). Chronic administration of benzodiazepines - V. Rapid onset of behavioral and neurochemical alterations after discontinuation of alprazolam. Neuropharmacology 29: 237-241.

McIntyre IM, Norman TR, Burrows GD, Armstrong SM (1993). Alterations to plasma melatonin and cortisol after evening alprazolam administration in humans. Chronobiol Int 10: 205-213.

Mellman TA, Uhde TW (1986). Withdrawal syndrome with gradual tapering of alprazolam. Am J Psychiatry 143: 1464-1466.

Melsom M, Andreassen P, Melsom H, Hansen T, Grendahl H, Hillestad LK (1976). Diazepam in acute myocardial infarction. Clinical effects and effects on catecholamines, free fatty acids, and cortisol. Br Heart J 38: 804-810.

Noyes Jr R, Clancy J, Coryell WH, Crowe RR, Chaudhry DR, Domingo DV (1985). A withdrawal syndrome after abrupt discontinuation of alprazolam. Am J Psychiatry 142: 114-116.

Noyes Jr R, Garvey MJ, Cook BL, Perry PJ (1988). Benzodiazepine withdrawal: a review of the evidence. J Clin Psychiatry 49: 382-389.

Osman OT, Hsiao JK, Potter WZ (1993). Dose-dependent effects of intravenous alprazolam on neuroendocrine, biochemical, cardiovascular, and behavioral parameters in humans. Psychopharmacology (Berlin) 111: 295-300.

Owens MJ, Vargas MA, Knight DL, Nemeroff CB (1991). The effects of alprazolam on corticotropin-releasing factor neurons in the rat brain: acute time course, chronic treatment and abrupt withdrawal. J Pharmacol Exp Ther 258: 349-356.

Pecknold JC (1993). Discontinuation reactions to alprazolam in panic disorder. J Psychiatr Res 27(Suppl 1): 155-170.

Pomara N, Tun H, Dasilva D, Hernando R, Deptula D, Greenblatt DJ (1998). The acute and chronic performance effects of alprazolam and lorazepam in the elderly: relationship to duration of treatment and self-rated sedation. Psychopharmacol Bull 34: 139-153.

Pruneti C, Giusti M, Boem A, Luisi M (2002). Behavioral, psychophysiological and salivary cortisol modifications after shortterm alprazolam treatment in patients with recent myocardial infarction. Ital Heart J 3: 53-59.

Risby ED, Hsiao JK, Golden RN, Potter WZ (1989). Intravenous alprazolam challenge in normal subjects. Biochemical, cardiovascular, and behavioral effects. Psychopharmacology (Berlin) 99: 508-514.

Risse SC, Whitters A, Burke J, Chen S, Scurfield RM, Raskind MA (1990). Severe withdrawal symptoms after discontinuation of alprazolam in eight patients with combat-induced posttraumatic stress disorder. J Clin Psychiatry 51: 206-209. 
Rodriguez-Huertas F, Carrasco MS, Garcia-Baquero A, Coq FD, Freire J (1992). Changes in plasma cortisol and ACTH caused by diazepam, bromazepam, triazolam, and alprazolam in oral premedication. Rev Esp Anestesiol Reanim 39: 145-148.

Roy-Byrne PP, Cowley DS, Hommer D, Ritchie J, Greenblatt D, Nemeroff C (1991). Neuroendocrine effects of diazepam in panic and generalized anxiety disorders. Biol Psychiatry 30: 73-80.

Roy-Byrne PP, Risch SC, Uhde TW (1988). Neuroendocrine effects of diazepam in normal subjects following brief painful stress. J Clin Psychopharmacol 8: 331-335.

Santagostino G, Amoretti G, Frattini P, Zerbi F, Cucchi ML, Preda $S$ et al (1996). Catecholaminergic, neuroendocrine and anxiety responses to acute psychological stress in healthy subjects: influence of alprazolam administration. Neuropsychobiology 34: 36-43.

Schuckit MA, Hauger R, Klein JL (1992). Adrenocorticotropin hormone response to diazepam in healthy young men. Biol Psychiatry 31: 661-669.

Schweizer E, Rickels K (1998). Benzodiazepine dependence and withdrawal: a review of the syndrome and its clinical management. Acta Psychiatr Scand Suppl 393: 95-101.

Sevy S, Brown SL, Wetzler S, Kotler M, Molcho A, Plutchik R et al (1994). Effects of alprazolam on increases in hormonal and anxiety levels induced by meta-chlorophenylpiperazine. Psychiatry Res 53: 219-229.

Slak S (1986). Alprazolam withdrawal insomnia. Psychol Rep 58: 343-346.

Tormey WP, Dolphin C, Darragh AS (1979). The effects of diazepam on sleep, and on the nocturnal release of growth hormone, prolactin, ACTH and cortisol. Br J Clin Pharmacol 8: 90-92.

Torpy DJ, Grice JE, Hockings GI, Walters MM, Crosbie GV, Jackson RV (1993). Alprazolam blocks the naloxone-stimulated hypothalamo-pituitary-adrenal axis in man. J Clin Endocrinol Metab 76: 388-391.

Torpy DJ, Grice JE, Hockings GI, Walters MM, Crosbie GV, Jackson RV (1994). Alprazolam attenuates vasopressin-stimulated adrenocorticotropin and cortisol release: evidence for synergy between vasopressin and corticotropin-releasing hormone in humans. J Clin Endocrinol Metab 79: 140-144.

Vgontzas AN, Kales A, Bixler EO (1995). Benzodiazepine side effects: role of pharmacokinetics and pharmacodynamics. Pharmacology 51: 205-223.

von Moltke LL, Greenblatt DJ, Cotreau-Bibbo MM, Harmatz JS, Shader RI (1994). Inhibitors of alprazolam metabolism in vitro: effect of serotonin-reuptake-inhibitor antidepressants, ketoconazole and quinidine. Br J Clin Pharmacol 38: 23-31.

Vongsavan N, Pavasuthipaisit K, Rakprasitkul S, Kitiyanant Y (1990). Beta-endorphin, ACTH, and cortisol secretion in man during standardized oral surgical stress and effect of diazepam. J Med Assoc Thai 73: 443-449.

Wang RW, Newton DJ, Liu N, Atkins WM, Lu AY (2000). Human cytochrome P-450 3A4: in vitro drug-drug interaction patterns are substrate-dependent. Drug Metab Dispos 28: 360-366.

Wechsler D (1945). A standardized memory scale for clinical use. J Psychol 19: 87-95.

Wechsler D (1981). WAIS-Revised Manual. The Psychological Corporation: Cleveland, $\mathrm{OH}$.

Wolf B, Griffiths RR (1991). Physical dependence on benzodiazepines: differences within the class. Drug Alcohol Depend 29: $153-156$.

Woods JH, Katz JL, Winger G (1992). Benzodiazepines: use, abuse, and consequences. Pharmacol Rev 44: 151-347.

Zemishlany Z, McQueeney R, Gabriel SM, Davidson M (1990). Neuroendocrine and monoaminergic responses to acute administration of alprazolam in normal subjects. Neuropsychobiology 23: $124-128$ 